\title{
KESALAHAN PENYELESAIAN MATHEMATICAL WORD PROBLEM SISWA SMK TEKNIK DAN BISNIS SEPEDA MOTOR BERDASARKAN TAKSONOMI SOLO
}

\author{
Desi Rahmawati', Ai Tusi Fatimah², Yoni Sunaryo ${ }^{3}$ \\ 1,2,3Program Studi Pendidikan Matematika, Universitas Galuh, J.L. R. E. Martadinata No.150, Ciamis, Indonesia \\ Email: desirahmawati1989@gmail.com
}

\begin{abstract}
The purpose of this study is to describe students' errors in solving Mathematical Word Problems compiled based on the SOLO taxonomy. The research method is descriptive qualitative using test as a data collection technique. The subjects of this study are six students of Al-Masturiyah Langkaplancar Vocational School with competency of Motorcycle Engineering and Business representing high, medium, and low mathematical abilities. The results shows that conceptual errors are made by students in the category of moderate and low mathematics ability groups. The conceptual error made by the students is that they do not use the theorems or formulas which is in accordance with the prerequisites of the formula. Errors in using the data are made by all of capability groups in that they do not employ the appropriate data. Language interpretation errors are made by students in the medium and low ability groups, namely, errors in expressing mathematical daily language, and errors in interpreting symbols, graphs, and tables into mathematical language. Technical errors are only made by students in the medium group, namely, errors in writing the form of inequality. The error of drawing conclusions is made by all capability groups, namely, making inferences without a valid supporting reason and inferring invalid statements with logical reasoning.
\end{abstract}

Keywords: Errors, SOLO taxonomy.

\begin{abstract}
ABSTRAK
Tujuan dari penelitian ini adalah untuk mendeskripsikan kesalahan siswa dalam menyelesaikan Mathematical Word Problems yang disusun berdasarkan taksonomi SOLO. Metode penelitian yang digunakan adalah kualitatif deskriptif. Teknik pengumpulan data penelitian ini adalah tes dan wawancara. Subjek penelitian ini adalah enam orang siswa SMK Al-Masturiyah Langkaplancar Kompetensi Keahlian Teknik dan Bisnis Sepeda Motor yang mewakili kemampuan matematika tinggi, sedang, dan rendah. Hasil penelitian menunjukan bahwa kesalahan konsep dilakukan oleh siswa pada kelompok kemampuan matematika sedang dan rendah. Kesalahan konsep yang dilakukan adalah penggunaan teorema atau rumus oleh siswa tidak sesuai dengan kondisi prasyarat berlakunya rumus tersebut. Kesalahan menggunakan data dilakukan oleh semua kelompok kemampuan yaitu tidak menggunakan data yang seharusnya dipakai. Kesalahan interpretasi bahasa dilakukan oleh siswa pada kelompok kemampuan sedang dan rendah yaitu kesalahan dalam menyatakan bahasa sehari-hari dalam Bahasa matematika dan kesalahan menginterpretasikan simbol-simbol, grafik dan tabel ke dalam Bahasa matematika. Kesalahan teknis hanya dilakukan oleh siswa pada kelompok sedang yaitu kesalahan penulisan bentuk pertidaksamaan. Kesalahan penarikan kesimpulan dilakukan oleh semua kelompok kemampuan yaitu melakukan penyimpulan tanpa alasan pendukung yang benar dan melakukan penyimpulan pernyataan yang tidak sah dengan penalaran logis.
\end{abstract}

Kata Kunci: Kesalahan, Taksonomi SOLO

Cara sitasi: Rahmawati, D., Fatimah, A. T., \& Sunaryo, Y. (2021). Kesalahan penyelesaian mathematical word problem siswa smk teknik dan bisnis sepeda motor berdasarkan taksonomi solo. J-KIP (Jurnal Keguruan dan IImu Pendidikan), 2 (2), 47-54. 


\section{PENDAHULUAN}

Matematika merupakan ilmu tentang struktur yang terorganisir dengan baik. Menurut Suherman (2003), konsep-konsep matematika tersusun secara hierarkis, tersruktur, logis, dan sistematis mulai dari konsep yang paling sederhana sampai pada konsep yang paling kompleks. Dalam mempelajari matematika, siswa dituntut untuk dapat menghubungkan konsep-konsep matematika yang nantinya akan berguna dalam proses pemecahan masalah. Menurut Priyanto (2015), pemecahan masalah dalam matematika sekolah biasanya diwujudkan melalui word problem. Word problem merupakan soal yang dibuat dalam bentuk cerita serta berkaitan dengan kehidupan sehari-hari. Menurut Susanti (2017), word Problem cenderung lebih sulit untuk dipecahkan dibanding soal yang hanya mengandung bilangan. Dalam memecahkan word Problem, siswa harus mampu memahami isi soal tersebut, mengetahui obyek-obyek matematika yang harus diselesaikan, mampu memisalkannya ke dalam model matematika, kemudian mampu memilih operasi hitung yang tepat untuk menyelesaikan word Problem tersebut, hingga tahap akhir yaitu penyelesaian serta penarikan kesimpulan.

Word problem merupakan salah satu soal yang membutuhkan keterampilan dan berbagai cara penyelesaian untuk mendapatkan jawaban akhir. Word problem sering disebut sebagai soal tersamar karena dalam word problem terdapat informasi yang termuat dalam soal maupun yang tidak diketahui dalam soal sehingga dalam menyelesaikannya dibutuhkan kemampuan membaca yang baik. Kemampuan tersebut terlihat pada "pemahaman soal" yakni kemampuan memahami apa yang diketahui dari soal, apa yang ditanyakan dalam soal, apa saja informasi yang diperlukan, dan bagaimana dalam menyelesaikan soal. Siswa diharapkan dapat menafsirkan kata-kata dalam soal, melakukan kalkulasi dan menggunakan prosedur-prosedur relevan yang telah dipelajari (Raharjo \& Astuti, 2011). Hubungan yang ada dalam word problem sebagai bagian dalam pelajaran matematika sangat berkaitan erat dalam kehidupan sehari-hari yang tak lepas dari masalah-masalah yang membutuhkan pemecahan untuk mendapatkan jawaban yang memuaskan.

Berkenaan dengan langkah-langkah penyelesaian word problem, secara garis besar Polya (1973) menetapkan empat langkah yang dapat dilakukan agar siswa lebih terarah dalam menyelesaikan masalah matematika, yaitu understanding the problem, devising plan, carrying out the plan, dan looking back yang diartikan sebagai memahami masalah, membuat perencanaan, melaksanakan rencana, dan melihat kembali hasil yang diperoleh. Rendahnya rata-rata nilai Ujian Nasional tingkat SMA (bahasa) pada tahun 2018/2019 yaitu rata-rata 37,53, tingkat SMA (IPA) ratarata 39,33 , tingkat SMA (IPS) rata-rata 34,36 , dan tingkat SMK rata-rata 35,26 menunjukkan bahwa siswa masih mengalami kesulitan dalam menyelesaikan soal-soal matematika sehingga seringkali melakukan kesalahan dalam menyelesaikan soal yang diberikan dan menyebabkan rendahnya hasil belajar siswa. Dengan menganalisis kesalahan hasil belajar siswa tersebut, guru diharapkan dapat mengetahui kesalahan dan penyebabnya yang dilakukan siswa dalam menyelesaikan soal sehingga dapat digunakan sebagai informasi untuk perbaikan proses pembelajaran. Salah satu cara yang dapat digunakan untuk mengetahui kesulitan siswa yaitu dengan cara menelusuri penyebab kesalahan yang dilakukan siswa dalam menyelesaiakan soal matematika, dimana untuk mengetahui penyebab kesalahan tersebut dapat dilakukan dengan cara menganalisis kesalahan melalui respon (jawaban) yang diberikan siswa dari pemberian tes. Sementara itu untuk menentukan kualitas respon (jawaban) siswa dalam menjawab soal dapat dianalisis menggunakan taksonomi SOLO.

Taksonomi SOLO digunakan untuk mengetahui respon siswa dalam kemampuan pemecahan masalah sesuai dengan tingkatannya yaitu, level prastruktural, level unistruktural, level multistruktural, level relasional, dan level extended abstrak. Berdasarkan level taksonomi SOLO, kemampuan siswa bisa diukur melalui tingkata-tingkatan tersebut dengan membuat suatu soal pemecahan masalah dari yang mudah sampai dengan yang sulit. Adapun penjelasan dari masing-masing tingkatan taksonomi SOLO oleh Pesona (2018). Prastruktural adalah kemampuan siswa yang tidak melibatkan suatu informasi untuk meyelesaikan suatu 
permasalahan. Unistruktural adalah suatu kemampuan siswa yang hanya satu informasi saja yang dapat digunakannya tetapi sudah mendapatkan hasil atau penyelesaian. Multistruktural adalah kemampuan siswa yang dua atau lebih informasi yang bisa dikaitkan untuk mendapatkan penyelesaian suatu pemecahan masalah dan bisa digunakan suatu rumus yang saling berkaitan satu sama lain. Relasional adalah kemampuan siswa dalam menggunakan dua informasi atau lebih tidak secara langsung saling berkaitan dengan satu sama lain tetapi bisa menggunakan cara baru untuk bisa mendapatkan hasil atau penyelesaian. Extended Abstract adalah kemampuan siswa yang menggunakan suatu informasi ayang abstrakk dari suatu soal dan bisa mendapatkan informasi baru dari suatu permasalahan untuk bisa mendapatkan hasil atau penyelesaian.

\section{METODE PENELITIAN}

Jenis penelitian ini adalah kualitatif deskriptif. Penelitian ini berusaha untuk mendiskripsikan jenis kesalahan dilakukan siswa dalam menyelesaikan mathematical word problems dimana soal yang disusun didasarkan pada taksonomi SOLO. Jenis kesalahan yang akan didiskripsikan berdasarkan jenis kesalahan Subanji dan Mulyoto.

Subjek pada penelitian ini adalah enam siswa kelas X Kompetensi Keahlian TBSM Tahun Ajaran 2019/2020. Pengambilan subjek penelitian ini menggunakan teknik purposive sampling, artinya pengambilan sampel dengan pertimbangan tertentu. berdasarkan rekomendasi dari guru matematika kelas $X$ siswa dipilih sesuai kategori tingkat kemampuan. Kemampuan tinggi diambil dari dua siswa yang berada diperingkat 1 dan 2 . Dua siswa kemampuan sedang dipilih berdasarkan siswa yang mendapat peringkat 10 besar di kelasnya dan 2 siswa yang berkemampuan rendah diambil dari siswa yang mendapatkan peringkat 11 kebawah di kelasnya.

Teknik pengumpulan data yang digunakan dalam penelitian ini adalah dengan cara tes tertulis, wawancara, dokumentasi, dan triangulasi. Dalam penelitian ini teknik analisis data menggunakan teknik analisis yang dikemukakan oleh Milles dan Huberman (1992). Analisisi data ini terdiri dari tiga kegiatan yaitu reduksi, display (penyajian data), dan verifikasi (menarik kesimpulan).

\section{HASIL DAN PEMBAHASAN}

Penelitian ini membahas tentang macam-macam kesalahan siswa dalam menyelesaikan mathematical word problem dan faktor yang menyebabkan siswa salah dalam mengerjakan. Kesalahan yang dianalisis dalam penelitian ini adalah kesalahan menurut Soebanji dan Mulyoto yang meliputi kesalahan konsep, kesalahan menggunakan data, kesalahan interpretasi bahasa, kesalahan teknis dan kesalahan penarikan kesimpulan.

Data dari hasil penelitian ini diperoleh dari hasil pengerjaan soal tes dan wawancara dengan siswa kelas X TBSM. Peneliti memberikan tes kepada enam orang siswa via daring dimana soal sebelumnya sudah melaui proses validasi. Setelah tes dilakukan, peneliti memeriksa hasil jawaban dari subjek untuk mengidentifikasi letak kesalahan yang dilakukan oleh siswa. Setelah memeriksa hasil kerja siswa, peneliti melakukaan wawancara semi terstruktur kepada enam siswa tersebut. Wawancara ini bertujuan untuk mengetahui faktor-faktor penyebab siswa melakukan kesalahan dalam menyelesaikan mathematical word problems pada materi program linear.

Berdasarkan deskripsi hasil tes dan wawancara yang dilakukan pada ke enam siswa, maka dapat diketahui kesalahan-kesalahan yang dilakukan oleh siswa dalam menyelesaikan mathematical word problems pada materi pokok program linear. Melalui hasil analisis data diketahui pula penyebab dari kesalahan yang dilakukan oleh siswa. Kesalahan tersebut terdiri dari kesalahan konsep, kesalahan menggunakan data, kesalahan interpretasi bahasa, kesalahan teknis, dan kesalahan penarikan kesimpulan.

\section{Subjek Berkemampuan Matematika Tinggi (T1)}

Pada siswa $T 1$, jenis kesalahan yang dilakukan adalah kesalahan menggunakan data, dan kesalahan penarikan kesimpulan. Berikut jenis kesalahan dan penyebab kesalahan T1. 
Tabel 1. Jenis dan Penyebab Kesalahan Siswa T1

\begin{tabular}{|c|c|c|c|c|c|c|}
\hline \multirow[b]{2}{*}{ soal } & \multirow{2}{*}{$\begin{array}{l}\text { Level } \\
\text { Soal }\end{array}$} & \multicolumn{5}{|r|}{ Jenis kesalahan dan Penyebab } \\
\hline & & $\begin{array}{l}\mathrm{K} \\
\mathrm{K}\end{array}$ & KD & $\begin{array}{l}\mathrm{K} \\
\mathrm{B}\end{array}$ & $\begin{array}{l}K \\
T\end{array}$ & KS \\
\hline a & $\mathrm{U}$ & & & & & \\
\hline $\mathrm{b}$ & M & & & & & \\
\hline c & $\mathrm{R}$ & & $\begin{array}{l}\text { Tidak } \\
\text { teliti }\end{array}$ & & & Tidak memeriksa kembali jawaban akhir pada poin c. \\
\hline$d$ & $\mathrm{EA}$ & & $\begin{array}{l}\text { Tidak } \\
\text { teliti }\end{array}$ & & & $\begin{array}{l}\text { Penarikan kesimpulan yang salah pada poin c sehingga } \\
\text { mempengaruhi jawaban pada poin d. }\end{array}$ \\
\hline
\end{tabular}

Tabel 1. menunjukan bahwa T1 melakukan kesalahan pada level relasional dan extended abstract yaitu kesalahan menggunakan data (KD) yaitu tidak menggunakan data yang seharusnya dipakai.dan kesalahan penarikan kesimpulan (KS) yaitu melakukan penyimpulan tanpa alasan pendukung yang benar. Adapun penyebab kesalahan menggunakan data pada level relasional dan extended abstract sama, yaitu siswa tidak teliti dalam menjawab soal. Kesalahan penarikan kesimpulan (KS) pada level relasional disebabkan siswa tidak memeriksa kembali jawaban akhir pada poin c. sedangkan pada level extended abstract kesalahan penarikan kesimpulan disebabkan penarikan kesimpulan yang tidak logis pada poin c, sehingga mempengaruhi jawaban siswa pada poin d, yang berakibat pada penarikan kesimpulan akhir yang salah.

\section{Subjek Berkemampuan Matematika Tinggi (T2)}

Siswa T2 mampu menyelesaikan soal dengan benar sampai level multistruktural. Berikut jenis kesalahan dan penyebab kesalahan $\mathrm{T} 2$.

Tabel 2. Jenis dan Penyebab Kesalahan Siswa T2

\begin{tabular}{|c|c|c|c|c|c|c|c|}
\hline \multirow{2}{*}{ soal } & \multirow{2}{*}{ Level Soal } & \multicolumn{6}{|c|}{ Jenis kesalahan dan Penyebab } \\
\hline & & KK & KD & KB & KT & & KS \\
\hline a & $U$ & & & & & & \\
\hline$b$ & M & & & & & & \\
\hline c & $\mathrm{R}$ & & $\begin{array}{l}\text { Tidak } \\
\text { teliti }\end{array}$ & & & $\begin{array}{l}\text { Tidak memiliki } \\
\text { mengaitkan informas }\end{array}$ & $\begin{array}{l}\text { keterampilan dalam } \\
\text { si dalam penyelesaian }\end{array}$ \\
\hline$d$ & EA & - & - & - & - & & - \\
\hline
\end{tabular}

Tabel 2 menunjukkan bahwa subjek T2 melakukan kesalahan pada level relasional. Jenis kesalahan yang dilakukan adalah kesalahan menggunakan data (KD) yaitu tidak menggunakan data yang seharusnya dipakai, dan kesalahan penarikan kesimpulan (KS) yaitu melakukan penyimpulan tanpa alasan pendukung yang benar. Untuk level extended abstract, T2 tidak memberikan jawaban soal poin d. Penyebab kesalahan menggunakan data (KD) adalah siswa tidak teliti dalam menyelesaika soal. Sedangkan penyebab kesalahan penarikan kesimpulan (KS) adalah siswa tidak memiliki keterampilan dalam mengaitkan informasi dalam penyelesaian. Penyebab siswa tidak memberikan jawaban pada poin d untuk level soal extended abstract adalah siswa tidak dapat mengatur waktu pengerjaan soal dengan baik dan kurang memiliki keterampilan dalam menggunakan informasi untuk menyelesaikan mathematical word problems.

\section{Subjek Berkemampuan Matematika Sedang (S1)}

Siswa S-1 mampu menyelesaikan soal sampai level unistruktural. Berikut jenis kesalahan dan penyebab kesalahan Subjek S-1. 
Tabel 3. Jenis dan Penyebab Kesalahan Siswa S1

\begin{tabular}{|c|c|c|c|c|c|c|}
\hline \multirow{2}{*}{ Soal } & \multirow{2}{*}{$\begin{array}{c}\text { Level } \\
\text { Soal }\end{array}$} & \multicolumn{5}{|c|}{ Jenis Kesalahan dan Penyebab } \\
\hline & & KK & KD & KB & KT & KS \\
\hline a & U & & & & & \\
\hline b & M & $\begin{array}{l}\text { Kurang teliti } \\
\text { dalam } \\
\text { menuliskan } \\
\text { bentuk umum } \\
\text { fungsi objektif }\end{array}$ & $\begin{array}{l}\text { Tidak } \\
\text { teliti }\end{array}$ & $\begin{array}{l}\text { Kurang } \\
\text { memahami } \\
\text { makna } \\
\text { simbol } \\
\text { matematika }\end{array}$ & $\begin{array}{l}\text { Tidak teliti dan } \\
\text { terburu-buru } \\
\text { dalam } \\
\text { menyelesaika } \\
\text { n soal. }\end{array}$ & \\
\hline C & $\mathrm{R}$ & & $\begin{array}{l}\text { Tidak } \\
\text { teliti }\end{array}$ & & & $\begin{array}{l}\text { Terburu- } \\
\text { buru }\end{array}$ \\
\hline$d$ & EA & - & - & - & - & - \\
\hline
\end{tabular}

Tabel 3 menunjukkan bahwa subjek S1 melakukan kesalahan pada level multistruktural dan relasional. Pada level multistruktural, kesalahan yang dilakukan adalah kesalahan konsep (KK) yaitu penggunaan rumus yang tidak sesuai. Penyebabnya adalah siswa kurang teliti dalam menuliskan bentuk umum dari persamaan fungsi objektif. Selanjutnya, kesalahan menggunakan data (KD) yaitu tidak menggunakan data yang seharusnya dipakai. Penyebabnya adalah siswa kurang teliti dalam menyelesaikan soal. Kesalahan interpretasi bahasa (KB) juga dilakukan oleh siswa yaitu kesalahan dalam menyatakan bahasa sehari-hari dalam Bahasa matematika dan kesalahan menginterpretasikan simbol-simbol, grafik dan tabel ke dalam bahasa matematika. Penyebabnya adalah siswa kurang memahami makna simbol dan kurang terampil memahami pernyataan matematika. masih di level multistruktural, kesalahan yang dilakukan adalah kesalahan teknis (KT) yaitu kesalahan penulisan operasi aljabar fungsi. Penyebabnya adalah siswa kurang teliti dan terburu-buru dalam menuliskan pertidaksamaan.

Pada level relasional, kesalahan yang dilakukan siswa S1 adalah kesalahan menggunakan data (KD) yaitu tidak menggunakan data yang seharusnya dipakai. Penyebabnya kurang teliti dalam menyelesaikan soal. Siswa juga melakukan kesalahan penarikan kesimpulan, yaitu melakukan penyimpulan tanpa alasan pendukung yang benar. Penyebabnya adalah siswa terburu-buru sehingga tidak memeriksa kembali jawaban akhirnya. Sedangkan untuk poin $d$, soal level extended abstract, siswa S1 tidak memberikan jawaban. Penyebabnya adalah siswa tidak dapat mengatur waktu pengerjaan soal dengan baik.

\section{Subjek Berkemampuan Matematika Sedang (S2)}

Siswa S2 mampu menyelesaikan soal dengan benar sampai level multistruktural. Berikut jenis kesalahan dan penyebab kesalahan Subjek S-2.

Tabel 4. Jenis Kesalahan dan penyebab Siswa S2

\begin{tabular}{|c|c|c|c|c|c|}
\hline \multirow[b]{2}{*}{ Soal } & \multirow[b]{2}{*}{ Level Soal } & \multicolumn{4}{|c|}{ Jenis Kesalahan dan Penyebab } \\
\hline & & KK & KD & $\begin{array}{l}K \\
B\end{array}$ & KS \\
\hline$a$ & $U$ & & & & \\
\hline$b$ & M & & & & \\
\hline C & $\mathrm{R}$ & $\begin{array}{l}\text { Lupa cara } \\
\text { menentukan } \\
\text { daerah himpunan } \\
\text { penyelesaian }\end{array}$ & $\begin{array}{l}\text { Tidak } \\
\text { teliti }\end{array}$ & & $\begin{array}{l}\text { Siswa hanya sekedar } \\
\text { mengarang jawaban }\end{array}$ \\
\hline$d$ & EA & & $\begin{array}{l}\text { Tidak } \\
\text { teliti }\end{array}$ & & $\begin{array}{l}\text { Penarikan kesimpulan } \\
\text { yang salah pada poin c } \\
\text { sehingga mempengaruhi } \\
\text { jawaban pada poind }\end{array}$ \\
\hline
\end{tabular}


Tabel 4 menunjukan bahwa S2 melakukan kesalahan pada level relasional dan extended abstract yaitu kesalahan menggunakan data (KD) yaitu tidak menggunakan data yang seharusnya dipakai, kesalahan penarikan konsep (KK) yaitu tidak menggunakan teorema yang berlaku untuk menentukan daerah himpunan penyelesaian dan kesalahan penarikan kesimpulan (KS) yaitu melakukan penyimpulan tanpa alasan pendukung yang benar Adapun penyebab kesalahan menggunakan data (KD) pada level relasional dan extended abstract sama, yaitu siswa tidak teliti dalam menjawab soal. Kesalahan konsep (KK) pada level relasional disebabkan siswa lupa cara menentukan daerah himpunan penyelesaian sehingga siswa cenderung asal mengarsir daerah himpunan penyelesaian. Akibatnya siswa melakukan kesalahan dalam menarik kesimpulan (KS). sedangkan pada level extended abstract kesalahan penarikan kesimpulan disebabkan penarikan kesimpulan yang tidak logis pada poin c, sehingga mempengaruhi jawaban siswa pada poin d, yang berakibat pada penarikan kesimpulan akhir yang salah.

\section{Subjek Berkemampuan Matematika Rendah (R1)}

Siswa R1 mampu menyelesaikan soal sampai level unistruktural. Berikut jenis kesalahan dan penyebab kesalahan Subjek R1.

Tabel 5. Jenis dan Penyebab Kesalahan Siswa R1

\begin{tabular}{|c|c|c|c|c|c|c|c|}
\hline \multirow{2}{*}{ Soal } & \multirow{2}{*}{$\begin{array}{c}\text { Level } \\
\text { Soal }\end{array}$} & \multicolumn{6}{|c|}{ Jenis Kesalahan dan Penyebab } \\
\hline & & KK & KD & KB & KT & & KS \\
\hline a & U & & & & & & \\
\hline b & M & & $\begin{array}{l}\text { Tidak } \\
\text { teliti }\end{array}$ & $\begin{array}{l}\text { Kurang } \\
\text { memahami } \\
\text { makna simbol } \\
\text { matematika }\end{array}$ & & & \\
\hline C & $\mathrm{R}$ & & $\begin{array}{l}\text { Tidak } \\
\text { teliti }\end{array}$ & & $\begin{array}{l}\text { Terburu- } \\
\text { buru }\end{array}$ & & \\
\hline d & EA & & $\begin{array}{l}\text { Tidak } \\
\text { teliti }\end{array}$ & & & $\begin{array}{l}\text { Data } \\
\text { valid }\end{array}$ & digunakan tidak \\
\hline
\end{tabular}

Tabel 5 menunjukan bahwa R1 melakukan kesalahan pada level multistruktural, relasional dan extended abstract. Kesalahan menggunakan data (KD) terjadi pada ketiga level tersebut, yaitu tidak menggunakan data yang seharusnya dipakai. Penyebabnya semua sama, siswa tidak teliti dalam menyelesaikan mathematical word problem. Pada level multistruktural, siswa juga melakukan kesalahan interpretasi bahasa (KB) yaitu kesalahan dalam menyatakan bahasa sehari-hari dalam bahasa matematika dan kesalahan menginterpretasikan simbol-simbol, grafik dan tabel ke dalam Bahasa matematika. Penyebabnya adalah siswa yang masih kesulitan memahami maksud dari soal tersebut. Pada level relasional siswa melakukan kesalahan penarikan kesimpulan (KS) yaitu siswa Melakukan penyimpulan tanpa alasan pendukung yang benar. Akibatnya mempengaruhi jawaban siswa pada poin d, sehingga jawaban akhir atau kesimpulan dari siswa tidak tepat.

\section{Subjek Berkemampuan Matematika Rendah (R2)}

Siswa pada kemampuan matematika rendah R2 melakukan kesalahan konsep pada level prastruktural. Tingkat prastruktural yaitu tingkat dimana siswa hanya memiliki sedikit sekali informasi yang bahkan tidak saling berhubungan, sehingga tidak membentuk sebuah kesatuan konsep sama sekali dan tidak mempunyai makna apapun. Dengan kata lain siswa belum bisa mengerjakan soal yang diberikan secara tepat, siswa tidak memiliki keterampilan yang dapat digunakan dalam menyelesaikan soal, bahkan siswa tidak memahami apa yang harus dikerjakan. Salah satu hal yang terlihat pada tingkat ini siswa tidak dapat menuliskan hal yang diketahui serta hal yang ditanyakan dalam soal, tidak mengetahui apa isi soal, tidak dapat menganalisa apa maksud soal, dan tidak dapat menuliskan simbol-simbol matematika dengan baik. Siswa cenderung tidak memberikan jawaban atas soal yang diberikan. Penelitian yang menguatkan yaitu hasil penelitian Asikin (2002) yang menyimpulkan diantaranya bahwa pada tingkat prastruktural peserta didik menolak memberi jawaban, menjawab secara atas dasar pengamatan dan tanpa dasar yang logis. 


\section{KESIMPULAN}

Berdasarkan hasil penelitian dan pembahasan, dapat diambil simpulan untuk menjawab pertanyaan penelitian adalah sebagai berikut.

1. Kesalahan konsep

Kesalahan konsep terjadi pada level prastruktural dan multistruktural. Kesalahan konsep yang dilakukan yaitu kesalahan menentukan teorema atau rumus untuk menjawab suatu masalah. Penyebabnya adalah kurang telitinya siswa dalam mengerjakan soal dan lupa dengan rumus yang harus digunakan.

2. Kesalahan menggunakan data

Kesalahan menggunakan data paling banyak dilakukan di tingkat multistruktural dan relasional. Adapun kesalahan yang dilakukan siswa antara lain siswa tidak menggunakan data yang seharusnya dipakai dan kesalahan memasukkan data ke variabel. Penyebabnya adalah kurang telitinya siswa dalam mengerjakan soal

3. Kesalahan interpretasi bahasa

Kesalahan interpretasi bahasa terjadi pada level multistruktural. Kesalahan yang dilakukan siswa yang termasuk kedalam kesalahan interpretasi bahasa adalah kesalahan dalam menyatakan bahasa sehari-hari dalam Bahasa matematika dan kesalahan menginterpretasikan symbol-simbol, grafik dan tabel ke dalam Bahasa matematika.

4. Kesalahan teknis

Kesalahan teknis terjadi pada level multistruktural. Kesalahan yang dilakukan siswa yang termasuk kedalam kesalahan teknis adalah kesalahan manipulasi dan penulisan operasi aljabar. Penyebabnya adalah siswa tidak teliti dalam menyelesaikan soal.

5. Kesalahan penarikan kesimpulan

Kesalahan penarikan kesimpulan terjadi pada level relasional dan extended abstract. Kesalahan yang dilakukan siswa dalam penarikan kesimpulan antara lain melakukan penyimpulan tanpa alasan pendukung yang benar dan melakukan penyimpulan pernyataan yang tidak sah dengan penalaran logis. Penyebabnya adalah siswa yang tergesa-gesa dalam menyelesaikan soal sehingga tidak meninjau kembali hasil akhir dari penyelesaian yang diberikan.

\section{REKOMENDASI}

Hasil penelitian diharapkan dapat memberikan sedikit sumbangan pemikiran sebagai usaha meningkatkan kemampuan dalam bidang pendidikan dan khususnya bidang matematika. Saran yang dapat penulis sumbangkan sehubungan dengan hasil penelitian kepada peneliti selanjutnya, jika ada satu atau lebih subjek yang belum memenuhi tingkatan berdasarkan taksonomi SOLO agar bertanya kepada subjek tersebut lebih mendalam lagi.

\section{UCAPAN TERIMAKASIH}

Penulis mengucapkan terima kasih kepada pihak-pihak yang membantu dalam penulisan artikel ini.

\section{DAFTAR PUSTAKA}

Agustina, I. R., Mulyono., \& Asikin, M. (2016). Analisis Kesalahan Kelas VIII Dalam Menyelesaikan Soal Matematika Bentuk Uraian Berdasarkan Taksonomi SOLO. Unnes Journal of Mathematics Education. 5(2), 92-100. doi: https://doi.org/10.15294/ujme.v5i2.11399.

Asikin, M. (2002). Penerapan Taksonomi Solo Dalam Pengembangan Item Tes Dan Interpretasi Respon Mahasiswa pada Perkuliahan Geometri Analitika. Semarang: Lemlit UNNES.

Manibuy, R.,dkk. (2014). Analisis Kesalahan Siswa Dalam Menyelesaiakn Soal Persamaan Kuadrat Berdasarkan taksonomi SOLO Pada Kelas X SMA Negeri 1 Plus di Kabupaten Nabire-Papua. Jurnal Elektronik Pembelajaran Matematika, 2(9), 933-945. Retrieved from https://www.jurnal.fkip.uns.ac.id/index.php/s2math/article/view/4834 
Miles dan Huberman. 1992. Analisis data Kualitatif. (diterjemahkan Ole: Tjetjep Rohedi Rosidi). Jakarta: Universitas Indonesia

Pesona, R.E., \&Yuanita,T.H. (2018). Deskrpsi Kemampuan Matematika Siswa dalam Pemecahan Masalah Sistem Persamaan Linear Dua Variabel Berdasarkan Level Taksonomi SOLO. Genta Mulia, 9(01), 99-109

Priyanto, A., Suharto, \& Trapsilasiwi, D. (2015). Analisis Kesalahan Siswa Dalam Menyelesaikan Soal Cerita Pokok Bahasan Teorema Pythagoras Berdasarkan Kategori Kesalahan Newman di Kelas VIII A SMP Negeri 10 Jember. Artikel IImiah Mahasiswa1(1), 1-5.

Polya, G. 1973. How to Solve it. New Jersey: Princeton University Press.

Raharjo dan Astuti. (2011). Pembelajaran Soal Cerita Operasi Hitung Campuran di Sekolah Dasar. www.p4tkmatematika.org (diakses 7 April 2020)

Suherman, E., etc. (2003). Strategi Pembelajaran Matematika Kontemporer. Bandung : UPI

Susanti. (2017). Analisis Kesalahan Siswa Dalam Menyelesaikan Soal Cerita Program Linier Berdasarkan Tahapan Newman. Jurnal Ilmiah Pendidikan Matematika2 (6), 71-76. 